\title{
Influence of Real-Information to Change Tourists' Travel Route
}

\author{
Qingyun Chen, Ruimin Ma, Maozhu Jin* and Peiyu Ren \\ Business School, Sichuan University \\ jinmaozhu@scu.edu.cn
}

\begin{abstract}
The tourism system as a whole is becoming less sustainable, both because of its overall rapid growth and the unwillingness to change travel behavior (tourists). In the field of the tourism, the tourists' activities have influences on the protection and development of the natural scenic. In order to understand the tourist' intention to change travel route based on real-time information, this paper adds trust to the model of theory of planned behavior $(T P B)$. Exploratory and confirmatory factor analysis are used to identify and confirm the constructs. In addition, structural equation modeling was established to test the measure model. Results indicate that the attitude, subjective norm and perceived behavioral control have positive effect on the behavioral intention of changing travel route according to real-time information. Moreover, trust also has positive influence on behavioral intention via three antecedents of intention. The findings have implications for predicting the tourist's intention of travel route change.
\end{abstract}

Keywords: Theory of planned behavior (TPB); Real-time information; Structural equation modeling

\section{Introduction}

Recent years, with the development of economy and the increase of people's income, more and more people attach importance to the spiritual pursuit and tourist numbers are rising rapidly, which bring a shock to the protection of the natural scenic spot [1]. Actually, environmental protection of natural scenic area depends on effective management, reasonable vehicle scheduling, pricing measures and effective diversion scheme, while the implementation of the above measures relied heavily on the information level. There are more and more attentions have paid to the construction of information platform in scenic spot. The managers of scenic area introduce advanced information technology to guide the tourist's travel route choice, and relieve the congestion in scenic spot. Some individuals also have moved considerably in adjusting their behaviors with the guidance of system of scenic area to become more environmentally, economically and socially responsible. The whole process of tourism generally can be divided into three stages, destination choice, tourist sightseeing and evaluation after visiting the scenic spot. Most researches concentrate on the first and third stages.

A lot of scholars have studied the tourist choice behavior intention of tourism destination. Lam and Hsu [2] use core constructs (attitude, subjective norm and perceived behavioral control) of the Theory of planned behavior (TPB) model, with the additional of past behavior, to behavioral intention of choosing a travel destination. Spark [1] apply exploratory and confirmatory factor analyses on three wine tourism attitudinal dimensions, and employed structural equation modeling to predict tourist behavioral intentions. The literature [3] has studied the interrelationships among electronic word of mouth (eWOM), destination image, tourist attitude, and travel intention in the tourism

${ }^{*}$ Corresponding Author 
industry. Moreover, many scholars such as [4] and [5] etc., also addressed some research on travel destinations and travel intentions. As for the third stage, the evaluation of a destination can be reflected on the satisfactory and loyalty. Many research presented for the tourist satisfaction and destination loyalty [6-9]. According the summary above we can know that, most literature about tourism are concentrated in the activities before entering the scenic and the overall evaluation after leaving the scenic, but few scholars were interested in the visiting process and the behavioral intention.

With the development of information technology and the increasing of people meet demand, the scenic area management tends to enhance the work of informationization and intellectualization. Modern information technology has always been throughout the tourists around the entire visit process, and managers need some compulsory measures or leading information to shunt the tourists especially during the peak tourist time. The guidance information provides tourist with real-time information about traffic conditions, accident delays and route guidance from origin to destination. If tourists know about the overall situation of the next scenic spots ahead of time, then they could make a good planning and reasonable visit route. Many scholars have studied the route selection based on real-time information. The Research [11] pointed out that travelers' changes are likely to be sensitive to the accuracy of the provided information in addition to travel time uncertainty, and prescriptive information has the largest behavioral impact followed by descriptive and experiential feedback information. In the case of descriptive information, several SP experiments [12] assert that travelers will tend to exhibit risk aversion when faced with travel time information. Dia [13] presented an agent-based approach to modeling individual driver behavior under the influence of real-time traffic information. Literature [14] investigated route switching behavior on freeways in reaction to the provision of different types of real-time traffic information. The provision of real-time travel information is increasingly being recognized as a potential strategy for influencing driver behavior on route change, trip making, times of travel and mode. Similarly, the real-time information in the scenic can also influence tourist behavioral intention on route change.

This study mainly addresses a research on the influence of real-time information from scenic to the intention of tourist's route change. Aim at forecasting tourist's behavioral intention after receiving real-time information and providing feasible suggestions for scenic spot management. To investigate the process, this paper applies the theory planned behavior (TPB) as the research framework to predict the behavioral intention of tourist changing their routes after receiving the real-time information from the manager of scenic. TPB, a widely used model to predict and explain human behavior, has been applied to a variety of social behaviors with strong predictive utility [15-17]. Furthermore, additional constructs are suggested to enhance the predictive power of TPB (Chow and Chan 2008), and thus this study employs trust for the following reasons.

During travel activities, good quality tours which usually mean safe traveling could enhance tourists' positive impressions over the trip and encourage future revisiting [18].Correspondingly, the safety for travel vehicles plays a pivotal role in a tour. According to some researches, trust can be considered a conspicuous behavioral belief which exerts an influential effect on the antecedents of behavioral intention - that is, attitude, perceived behavioral control, and subjective norm. In rest of this section, the theory would be reviewed and the hypothesis development among these factors would be depicted.

\subsection{The Theory of Planned Behavior}

According to the theory of reasoned action, if people evaluate the suggested behavior as positive (attitude), and if they think their significant others want them to perform the behavior (subjective norm), this results in a higher intention (motivations) and they are more likely to do so. A high correlation of attitudes and subjective norms to behavioral 
intention, and subsequently to behavior, has been confirmed in many studies. TRA could adequately predict behaviors under volitional control, but under circumstances where there are constraints on action, the mere formation of an intention is insufficient to predict behavior. Thus, the inclusion of $\mathrm{PBC}$ is necessary to improve the predicting power of intention. Therefore, an additional construct of perceived behavioral control (PBC), which originates from self-efficacy theory (SET) [23] - an antecedent variable affecting both intentions and behavior- has been added to the TRA model by Ajzen.

The theory of planned behavior (TPB) is a well-researched model which is widely used in explaining and in predicting human behavior across a variety of disciplines [10], such as marketing consumer behavior [13], leisure behavior [17], and disease prevention [24]. Thus, TPB proposes that three key constructs will drive behavior: attitude, subjective norms and perceived behavior control. An attitude is the overall evaluation of the behavior and reflects feelings of favorableness or un-favorableness toward performing a behavior; a subjective norm is the influence of others about whether to engage in the behavior; and control is the perceived ability to engage in the behavior.

Behavioral intention (BI) is the individual's subjective probability that he or she will engage in that behavior. According to TPB, the immediate determinant of a behavior is the individual's intention to perform or not perform that behavior. Therefore, if there is an opportunity to act and the intention is measured accurately, then it will provide the best predictor of behavior. This paper addresses a research on the influence of the real time information on the tourists' behavior intentions (BI) to changing their routes.

Researchers agree that attitude, subjective norm, perceived behavioral control toward a behavior exerts a positive influence on a person's intention to perform the behavior [1,2526]. Even though the relative weights of these three antecedents of intention are expected to vary with the kind of behavior being predicted and with the conditions under which the behavior is to be taken. A lot of literature have confirmed that attitude, subjective norms and perceived behavior control have strong, direct, and positive effect on intentions [10].

Hypothesis 1. Attitude is positively related to the tourists' intention to changing their routes under the real-time information from scenic.

Hypothesis 2. Subjective norms will have direct effects on a tourist's intention to changing he/her route under the real-time information from scenic.

Hypothesis 3. Perceived behavior control will have direct effects on a tourist's intention to his/her route change under the real-time information from scenic.

\subsection{Trust and TPB}

Trust can be defined as a willingness to rely on an exchange in which one has confidence [14]. Psychologists define trust as an individual's generalized expectation that the promise of another individual can be relied upon [31]. Trust is at the heart of all kinds of relationships [32]. The nature of trust deals with the belief that the trusted party will fulfill its commitments, despite the trusting party's dependence and vulnerability [2, 3334]. Many Researches have demonstrated that the need for trust appears in any supplier/client business relationship characterized by a high degree of risk, uncertainty, and/or a lack of knowledge or information on consumer parts. Risk and uncertainty increase under situations whereby consumers are not able to examine physical products before purchase [3]. In such a case, the need for trust is particularly important.

However, trust in this study is about the perception of real-time information from scenic, which will influence the decision making when tourist change a travel route. Perception refers to an individual's knowledge, information, and experiences which are responsive to their cognition of objects, behaviors, and events [35]. People have formed their attitudes, interests, and opinions through the perceptions which they acquire in their day-to-day lives. Trust in information system is a viable concept since it reflects the willingness of the trustor to "behaviorally depend on a piece of software to do a task". Trust is studied in various dimensions. Yet, the most significant aspect of it is when trust 
is defined as a set of specific beliefs about benevolence, ability and integrity, which is labeled as trustworthiness in [36].

For the attitude construct, early in 1993, the paper [37] has founded that high levels of trust by buyers have been found to motivate favorable attitudes and behavior. Similarly, other studies also have indicated that trust can be a direct influencer that determines people's attitude toward behavior [20-21].

In the study of information system, peers and superiors are found to have certain influences on subjects for information system (IS) usage [38]. Similarly, the tourists may be influenced by the judgment of people around them (companion or stranger), when someone else trust the real-time information from scenic, they would chose to believe the information is reliable. Mutual trust within a group improves interactions between members [39].

Mutual trust between customers and merchants enhances customers' self-efficacy, and in turn, increases perceived behavior control [19]. Fang, Shao and Lan [26] presents that trust exerted moderate effects on participation attitude and perceived behavioral control, which in turn significantly affected participation intention. Hsiao and Yang [21] addresses a research on the college students' intention to take high speed rail, and concludes that the trust has indirect effect on behavioral intention, through the three antecedents of intention: attitude, subjective norm, perceived behavioral control. The same to the tourists' intention to route change with the real-time information.

Hypothesis 4. Trust will have direct effect on attitude to route change based on the real-time information from scenic.

Hypothesis 5. Trust will have direct effect on subjective norm to route change based on the real-time information from scenic.

Hypothesis 6. Trust will have direct effect on perceived behavioral control to route change based on the real-time information from scenic.

\section{Method}

\subsection{Participants}

Participants were tourists from nature scenic, such as Jiuzhai Valley. All 320 tourists were invited to participate in the survey, and 301(94\%) of them provided useable responses.

\subsection{Questionnaire Development}

Based on TPB, the questionnaire was designed to collect information on the likelihood of changing travel route according to real-time information from scenic(behavioral intention); likely outcomes of changing route according to real-time information(attitude); Groups or individuals whose views might influence respondents' selection of following the real-time information(subjective norms); Factors that might facilitate or inhibit the route change(perceived behavioral control); and the trust to the real-time information.

Attitude: Attitude was measured by five statements, ranging from strongly agree (5) to strongly disagree (1), using semantic differential scales: "Changing the travel route according to the real-time information from scenic would be..."good-bad; wise-unwise; correct-incorrect.

Subjective norm: Five statements, each with a five-point Likert scale, were asked to evaluate subjective norm: "Views from family are important for my route change according to real-time information ", ranging from strongly agree (5) to strongly disagree (1). In additional, the other four statements: tour conductor, friend, classmate/colleague and stranger around are considered. 
Perceived behavioral control: Five statements were used to measure Perceived behavioral control, five-point Likert scale from strongly agree (5) to strongly disagree (1). A sample statement was: "It is easy for me to change travel route ".

Trust: Trust of the real-time information to change travel route was measured with five statements, ranging from strongly agree (5) to strongly disagree (1). A represent item was: "Based my perception with real-time information, I think it is very responsive to tourist ".

Behavioral intention: Behavioral intention of changing route according to the real-time information was measured by five statements with a five-point Likert scale from strongly agree (5) to strongly disagree (1).

\section{Results and Discussions}

\subsection{Demographic Profile}

The obtained sample represented a diversity of age group, tourism ways, people travel together, educational and economic backgrounds. As shown in Table 1, in terms of gender, there are more females in the research samples, altogether 167 women (55.5\%), and male (45.5\%). As for age, people aged between 25 and 34 accounts for the most of the sample, altogether 176, and that is $58.5 \%$ of the total; whereas people above 45 accounts for the least, only $4.7 \%$ of the total. In terms of education background, people who go to junior college and undergraduates are the most in the sample, altogether 229, and that is $76.2 \%$ of the total; people who go to junior middle school and below occupy the least, only $1.2 \%$ the total. As far as the total household income, middle-income people take up the most part in the sample, reach 104, and the percentage is $34.6 \%$ of the total, followed by the higher income people, the percentage of which arrives at $31.2 \%$; people whose income greater than $¥ 150,000$ reach the bottom, only $4.0 \%$ of the total. As for tourism way, most people, take up $56.6 \%$, prefer to independent travel; while the percentage of unit organization tourism occupy the least, only $1.2 \%$ the total. In terms of people travel together, majority people(51.8\%) like to travel with their family, and few people would like to travel without someone accompany.

\subsection{Test on the Validity and Reliability of the Questionnaire}

We collected 101 questionnaires with complete data across all variables to do the exploratory factor analysis (EFA). Principal Axis Factoring was performed on the full set of items intended to measure attitude, norms, perceived control, behavioral intention and trust. Principal Axis Factoring was used as it is recommended for consumer or behavioral research and is the most appropriate approach for use when developing factors for structural equation modeling. Bartlett's test of sphericity was $789.865(\mathrm{p}<0.001)$ and the Kaiser-Meyer-Olkin (KMO) measure of sampling adequacy was 0.770 which is well above the recommended index of 0.6. Table 2, show that the cumulative percentage of variance of the factors was $65.126 \%$. 
Table 1. Demographic Profile

\begin{tabular}{lc}
\hline Sample characteristic & $\%$ \\
\hline Gender & 44.5 \\
Male & 55.5 \\
Female & \\
\hline Age & 11.6 \\
$15-24$ & 58.5 \\
$25-34$ & 25.2 \\
$35-44$ & 4.7 \\
$45+$ & \\
\hline Total household income(Year)(Yuan) & 9.0 \\
Less than ¥30,000 & 21.2 \\
$¥ 30,000$ - ¥50,000 & 34.6 \\
$¥ 50,000$ - ¥80,000 & 31.2 \\
$¥ 80,000$ - ¥150,000 & 4.0 \\
Greater than ¥150,000 & 1.2 \\
\hline Education & 14.3 \\
Junior Middle School and below & 76.2 \\
Senior Middle School/ Technical Secondary School & 8.3 \\
Junior College/Undergraduate & \\
Postgraduate and beyond & 56.6 \\
\hline Tourism way & 36.9 \\
Independent travel & 6.6 \\
Travel agency & \\
Unit organization tourism & 51.8 \\
\hline People travel together & 34.9 \\
Family & 12 \\
Classmate/friend & 1.3 \\
Colleague & \\
None & \\
\hline
\end{tabular}

Cronbach's $\alpha$ will generally increase as the inter correlations among test items increase, and is thus known as an internal consistency estimate of reliability of test scores. Nunnally [40] and DeVellis [23] believed if the numerical values of $\alpha$ for all dimensions were above 0.700 , then it was very good. Hair (1998) stated that the standard of factor loading is related to the sample size, when the sample is 100 , the factor loading should be above 0.550 . The numerical value of $\alpha$ of the whole questionnaire should be bigger than the acceptable critical value 0.800 . The results are shown in Table 2 , which clearly reveals that all the value are satisfactory and indicates the measurement model have good content validity and discriminant validity. 
Table 2. Result of the Validity Test for Each Variable

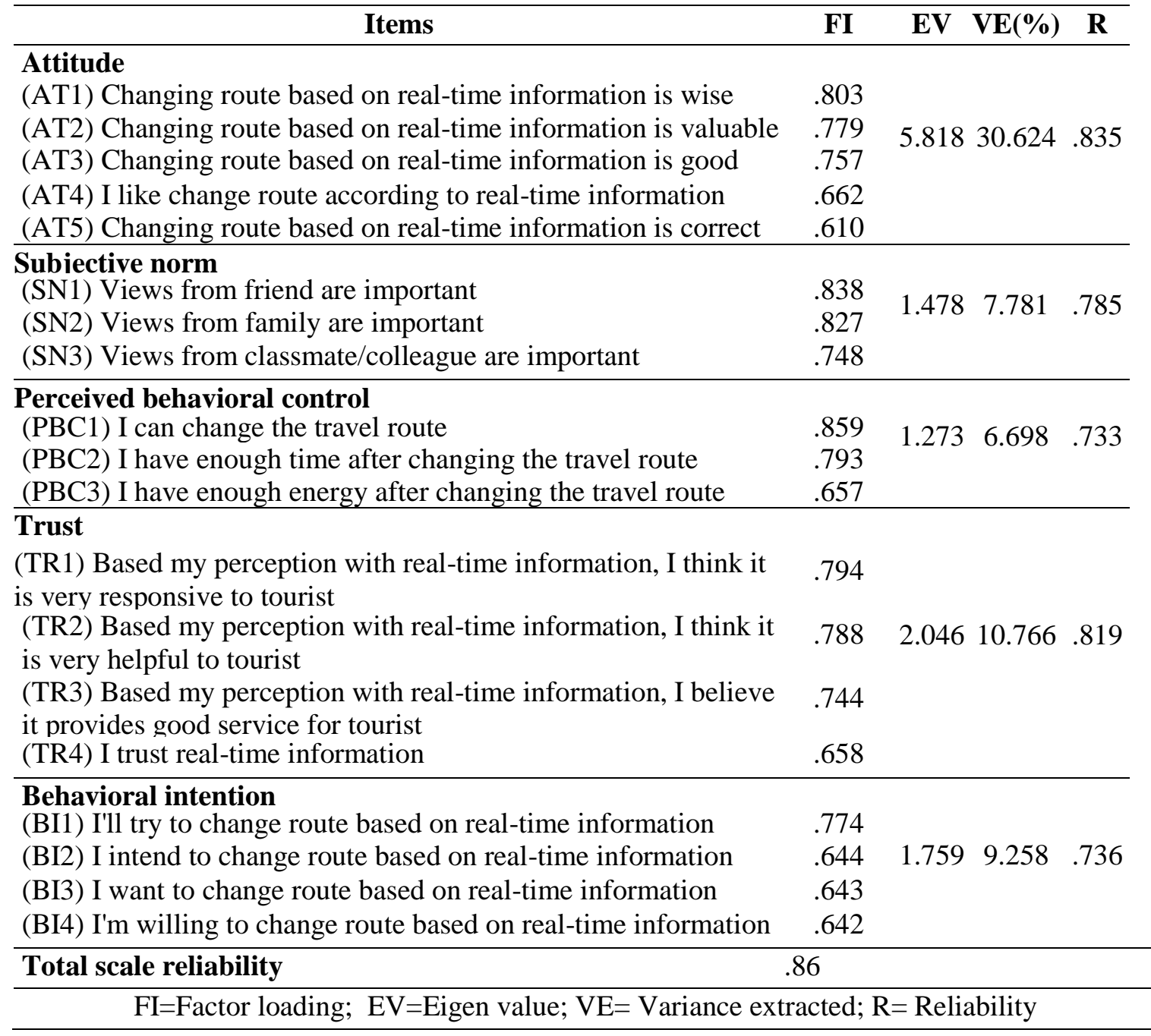

In order to examine the convergent validity of the measurement model, a confirmatory factor analysis (CFA) was run on the covariance matrix of the responses of the validation sample. Two main indicators are considered: Composite reliability (CR) and Average variance extracted (AVE). Chin [16] believed that when the value of CR is greater than 0.700, the factors of the model have good reliability. Literature [24] proposed that the CR should be above the acceptable critical value 0.600. For the AVE, Fornell and Larcker (1981) [30] stated that the acceptable value of AVE should be greater than 0.500, furthermore, The square root of the AVE for each construct must be greater than the correlation coefficient of the construct and other constructs. From Table 3, we can see that, our composite reliability (CR), ranging from 0.6874 to 0.8471 , all are exceed the recommend threshold of 0.6. In addition, the average variances extracted (AVE) range from 0.4655 to 0.6122 , which are also above the acceptable value of 0.500 except for the construct of behavioral intention. Moreover, the square root of the AVE for each construct is up to the standard. So the convergent validity of the measurement model is acceptable.

Meanwhile, Spicer (2005) [28] has demonstrated when the independent variable and dependent variable has a moderate high relevance, and has moderate or low correlation between independent variables themselves, the relationship is the best. As shown in Table 
3, behavioral intention (BI) and the independent variable has a moderate high relevance, while the correlation coefficients between the dependent variables are low.

Table 3. Composite Reliability (CR), Average Variance Extracted (AVE) and Correlations

\begin{tabular}{|c|c|c|c|c|c|c|c|}
\hline & $\overline{C R}$ & AVE & AT & SN & BI & TR & PBC \\
\hline AT & .8024 & .5347 & .7312 & & & & \\
\hline SN & .7776 & .5390 & $.313^{* *}$ & .7341 & & & \\
\hline BI & .6948 & .4655 & $.552 * *$ & $.317 * *$ & .6823 & & \\
\hline TR & .8471 & .6122 & $.375^{* *}$ & $.289 * *$ & $.485^{* *}$ & .7824 & \\
\hline PBC & .6874 & .5198 & $.265^{* *}$ & $.238 * *$ & $.329 * *$ & $.294 * *$ & .7210 \\
\hline
\end{tabular}

\subsection{Structural Equation Modeling}

In order to investigate the relationship among the criterion variable of behavioral intention, trust and the respective predictor variables of attitude, subjective norm, perceived behavioral control, the SEM was performed. Moreover, we mainly investigate the following indicators to validate the model: (a) the Satorra-Bentler chi-square $(\chi 2)$, outlined by Kline (2011) [32]. A $\chi 2 / \mathrm{df}$ ratio of less than 2.0 is considered indicative of a good fit, an done between 2 and 5 is indicative of a satisfactory fit. (b) the Root Mean Square Error of Approximation (RMSEA), Kaplan (2009) [31] believed that the value of RMSEA less than 0.05 can fit the model well, if between 0.05 and 0.08 is considered indicative of a mediocre fit. (c) the non-normed fit index(NNFI) and (d) the comparative fit index (CFI). For the NNFI and CFI, values over 0.90 are acceptable and over 0.95 are indicative of a good fit.

The fit of this structural model was satisfactory, Satorra-Bentler $\chi 2(146)=269.249$ $(\mathrm{p}<0.001), \chi 2 / \mathrm{df}=1.844, \mathrm{RMSEA}=0.053, \mathrm{NNFI}=0.923, \mathrm{CFI}=0.934$. Figure 1 shows that the model accounts for $62 \%$ of the variance in behavioral intention; the standardized direct effects on behavioral intention were 0.63 for attitude, $17 \%$ for subjective norm, and 0.25 for perceived behavioral control. The model accounts for $25 \%$ of the variance in attitude, for $15 \%$ of in subjective norm, and for $18 \%$ of in perceived behavioral control. The standardized direct effect on attitude for trust was 0.50 , on subjective norm for trust 0.39 , and on perceived behavioral control for trust 0.43 .

By examining the standardized path coefficients all the paths are significant at level 0.001, except for the path from subjective norm to behavioral intention which are significant at 0.017 levels. So, Hypotheses 1-3 are supported. More specifically, attitude $(b=0.63 ; p<0.001)$, subjective norm $(b=0.17 ; p=0.017)$, perceived behavioral control $(b=0.25 ; \mathrm{p}=0.001)$ predicted the behavioral intention of changing travel route according to real-time information from scenic. The results concur with the suggestion by Ajzen (1991) [29]. Among the three antecedents of intention, attitude has the greatest effect on behavioral intention to changing route based on real-time information. On the other hand, subjective norm has the least impact on behavioral intention. The result is also consistent with that of Ajzen (1992) [27] in that behavioral intentions are closely related to attitudes toward leisure activities, and to a lesser extent, to subjective norm. Similarly, Hypotheses 4-6 are supported $(b=0.50 ; \mathrm{p}<0.001 ; \mathrm{b}=0.39 ; \mathrm{p}<0.001 ; \mathrm{b}=0.43 ; \mathrm{p}<0.001$, respectively), suggesting the important relationship of trust with the three antecedents of behavioral intention. From the analysis above, we found that the indirect effect of trust on behavioral intention via three antecedents of intention is 0.49 , $(0.5 * 0.63+0.39 * 0.17+0.43 * 0.25)$. 
In conclusion, all the hypotheses are supported. Attitude is the major influential factors of intention, trust also exert their influence on behavioral intention via attitude, subjective norm and perceived behavioral control.

\section{Conclusion}

Results of this study demonstrated the utility of the TPB as a conceptual framework for predicting behavioral intention of changing travel route according to the real-time information from scenic. All the indices $\left(\chi^{2}, \chi^{2} / \mathrm{df}\right.$, RMSEA, NNFI, CPI) indicated that it is a moderately good fit the model. And our research model is well supported and all the hypotheses are confirmed. We draw out that attitude has the greatest impact on tourist' intention to changing travel route based on real-time information, followed by subjective norm, and the perceived behavioral control has the least influence. Furthermore, the construct trust also influence tourists' intention indirectly via the three antecedents of intention.

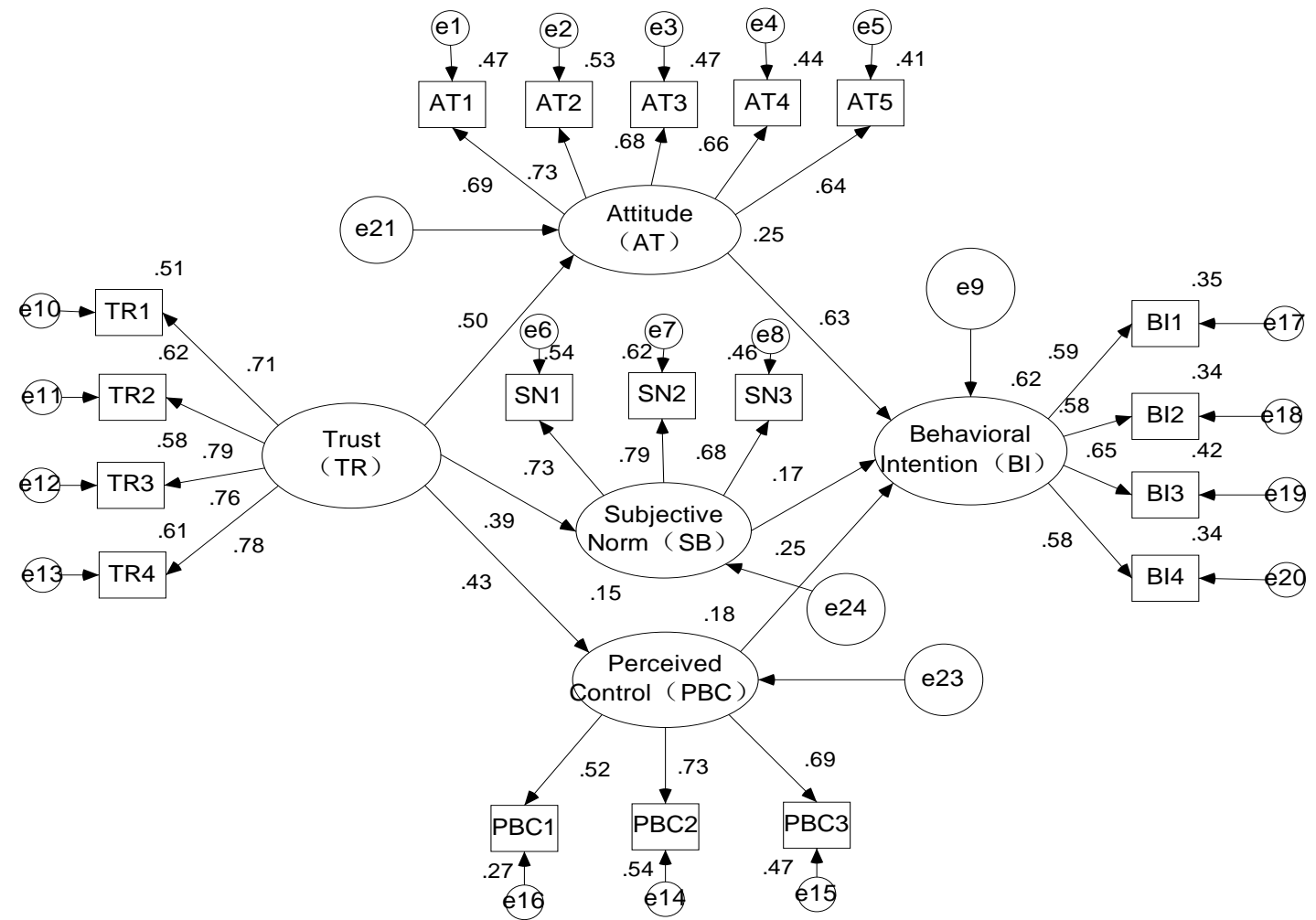

Figure 1. Final Model of the Route Changing Choice Intention

Based on findings of the study, a number of salient implications can be derived. Attitude from tourists was to be an important factor impacting their route change intention. Therefore, the managers of scenic can guide the tourist to change their route by enhancing a positive inclination about the real-time information. And it is necessary to emphasize that changing travel route according the real-time information is a good choice and will be helpful to their tourism. Next, the effect of perceived behavioral control on intention is also strong. The control variable indexed the amount of personal control a respondent felt they had over changing travel route. It comprised items that measured both time and energy control, so the managers should notice the importance the perceived barriers of time and energy. The managers should consider taking measures to let visitors be more convenient and quick for travel, such as an efficient vehicle scheduling scheme (reducing the waiting time and the time on the vehicle), a good road conditions and any 
measures can reduce the travel time and save travel energy. Last, the subjective norms measure, not unrelated to interpersonal barriers [22], also has an effect on intentions in the mediated structural model. This suggests that reference groups are influential in whether someone might changing travel route. Limited research is interested in the role of reference groups in determining route choice behavioral intention, which is worthy of exploration and can be extended to the driver's route choice behavioral intention.

The results show that trust has indirect significant influences on tourists' intention to change travel route based on real-time information via attitude, subjective norm and perceived behavioral control. It indicates that low intention to change travel route may be ascribed to unfavorable attitude, the effect of relevant groups and the perceptual resources, which in turn are influenced by the trust toward the real-time information. So, the scenic need to strength the information construction, managers of scenic should provide correct and reliable information to make the most travelers who followed the realtime information really gain high quality service, and let the tourist believe that changing route based real-time information is beneficial, similar to the statement of Berry (1995) [19] "trust is the basis for loyalty".

Like all studies, this study has limitation. First, the use of a convenient sample may impact the generalization of these findings, the samples used in the study are main from Jiuzhai Valley, owing to the high level information work, the information from scenic is always considered reliable and visitors in the scenic spot may be more willing to receive it. More samples from other nature scenic spot should be collected. Second, in this study, the analyses are based on data collected in a cross-sectional, one shot study and are thus subject to criticism of common method variance. To get a whole picture of route choice, the subsequent behavior of changing travel route formulation is needed. Finally, other important factors may influence the results are ignored, such as the spots have been visited, the time of investigation, the distance between two spots. If tourists have been visited the spot, they certainly not follow the information to revisit the spot. For tourists, in the morning, most spots in the scenic are not visited, while only few spots are not visited in the afternoon, there are big difference between the two situations.

\section{Acknowledgements}

The authors are grateful to the anonymous referee for a careful checking of the details and for helpful comments that improved this paper. This work was supported by the Natural Science Foundation of China (Grant No. 71371130 and 71001075), and China Scholarship Council.

\section{References}

[1] B. Sparks, Tourism Manage, vol. 28, no. 5, (2007).

[2] T. Lam and C. H. C. Hsu, Tourism Manage, vol. 27, no. 4, (2006).

[3] M. R. Jalilvand, N. Samiei, B. Dini and P. Y. Manzari, J. Destin. Mark. Manage, vol. 1, no. 1, (2012).

[4] H. J. Chen, P. J. Chen and F. Okumus, Tourism Manage, vol. 35, no. 4, (2013).

[5] T. Tessitore, M. Pandelaere and A. Van Kerckhove, Tourism Manage, vol. 42, no. 6, (2014).

[6] E. Avineri and J. N. Prashker, Transportation, vol. 33, no. 4, (2006).

[7] R. P. Bagozzi, J. Pers. Soc. Psycholo., vol. 41, no. 4, (1981).

[8] R. P. Bagozzi and Y. Yi, J. Acad. Market. Sci., vol. 16, no. 1, (1988).

[9] Y. Yue, J. H. Xiao and S. Y. Luo, Rev. Comput. En. Study, vol. 2, no. 4 (2015).

[10] D. Canca, A. Zarzo, E. Algaba and E. Barrena, Eur. J. Oper. Res., vol. 231, no. 2, (2013).

[11] E. Ben-Elia, R. Di Pace, G. N. Bifulco and Y. Shiftan, Transport. Res. C-Emer., vol. 26, (2013).

[12] A. Beerli and J. D. Martin, Ann. Tourism Res., vol. 31, no. 3, (2004).

[13] H. Dia, Transport. Res. C-Emer., vol. 10, no. 5, (2002).

[14] R. C. Jou, S. H. Lam, Y. H. Liu and K. H. Chen, Transport. Res. A- Pol, vol. 39, no. 5, (2005).

[15] Y. Z. Fan, Rev. Comput. En. Study, vol. 2, no. 2, (2015).

[16] W. W. Chin, in Modern methods for business research, Edited A. M. George, vol. 2, (1998), pp. 295-336.

[17] S. Cheng, T. Lam and C. H. C. Hsu, J. Hosp. Tourism Res., vol. 30, no. 1, (2006).

[18] C. G. Q. Chi and H. Qu, Tourism Manage, vol. 29, no. 4, (2008). 
[19] L. L.Berry, J. Acad. Market. Sci., vol. 23, no. 4, (1995).

[20] M. Conner and C. Abraham, Pers. Soc. Psychol. B., vol. 27, no. 11, (2001).

[21] C. H. Hsiao and C. Yang, Transportation Res F-Traf., vol. 13, no. 4, (2010).

[22] D. W. Crawford, E. L. Jackson and G. A Godbey, Leisure Sci., vol. 13, no. 4, (1991).

[23] R. F. DeVellis, Editor, Sage Publications, (2011).

[24] A. Diamantopoulos and J. A. Thousand oaks, New Delhi, Sage Publications, London, (2000).

[25] I. Ajzen, in SSSP Springer Series in Social Psychology, edited J.Kuhl and J. Beckmann. Springer Berlin Heidelberg, (1985).

[26] J. Fang, P. Shao and G. Lan, Comput. Hum. Behav., vol. 25, no. 1, (2009).

[27] I. Ajzen and B. Driver, J. Leisure Res., vol. 24, no. 3, (1992).

[28] J. Spicer, Making sense of multivariate data analysis: an intuitive approach. Sage (2005).

[29] I. Ajzen, Organ. Behav. Hum. Dec., vol. 50, no. 2, (1991).

[30] C. Fornell and D. F. Larcker, J. Market. Res., vol. 18, no. 1, (1981).

[31] D. Kaplan, in Structural equation modeling: Foundations and extensions, Sage Publication, (2009).

[32] R. B. Kline, in Principles and practice of structural equation modeling, Guilford press, (2011).

[33] R. C. Mayer, J. H. Davis and F. D. Schoorman, Acad. Manage. Rev., vol. 20, no. 3, (1995).

[34] T. Lam and C. H. C. Hsu, J. Hosp. Tourism Res., vol. 28, no. 4, (2004).

[35] R. M. Morgan and S. D. Hunt, J. Market., vol. 58, no. 3, (1994).

[36] D. Gefen, E. Karahanna and D. W.Straub, MIS Quart., vol. 27, no. 1, (2003).

[37] D. M. Rousseau, S. B. Sitkin, R. S. Burt and C. Camerer, Acad. Manage. Rev., vol. 23, no. 3, (1998).

[38] D. M. Randall and A. M. Gibson, J. Bus. Ethics., vol. 10, no. 2, (1991).

[39] J. Reinecke, P. Schmidt and I. Ajzen, J. Appl. Soc. Psychol., vol. 26, no. 9, (1996).

[40] J. C. Nunnally, in Psychometric Theory (2) McGraw-Hill, New York (1978). 
International Journal of $u-$ and e- Service, Science and Technology Vol. 9, No. 11 (2016) 